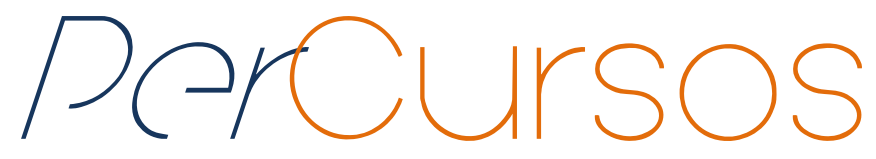

\title{
Quando "falham” políticas públicas, a vida corre perigo: a luta por moradia
}

\section{Resumo}

A presente escrita busca, através da reflexão crítica de uma Ação Civil Pública que objetiva a remoção de uma comunidade no município de Pelotas, no estado do Rio Grande do Sul, analisar macro processos de mercantilização da vida e financeirização do território urbano. Em termos metodológicos, busca relatar, a partir de um caso específico, como se desenvolve a negação do direito de habitar. Para isso, apresenta a legislação local e analisa a condução das políticas públicas para os interesses do mercado imobiliário na tentativa de denunciar o modelo de segregação territorial.

Palavras-chave: Habitação Popular; Desigualdade; Política Pública; Ocupação Irregular; Política Habitacional em Pelotas; Propriedade Territorial em Pelotas.

\author{
Nino Rafael Medeiros Kruger \\ Graduado em Serviço Social, \\ Mestre e Doutorando em Política \\ Social e Direitos Humanos pela \\ UCPel; Membro do Grupo de \\ Estudo e Pesquisa em Questão \\ Agrária, Urbana e \\ Ambiental/Observatório dos \\ Conflitos da Cidade. \\ contatorafaelkruger@gmail.com
}

\section{Cristine Jaques Ribeiro}

Doutora em Serviço Social pela PUC/RS; Docente de graduação em Serviço Social e do Programa de Pós-Graduação em Política Social e Direitos Humanos da UCPel; Coordenadora do Grupo de Estudo e Pesquisa em Questão Agrária, Urbana e Ambiental/Observatório dos Conflitos da Cidade. cristinejrib@gmail.com

\section{Para citar este artigo: \\ KRUGER, Nino Rafael Medeiros; RIBEIRO, Cristine Jaques. Quando "falham" políticas públicas, a vida corre perigo: a luta por moradia. Revista PerCursos, Florianópolis, v. 19, n.40, p. 39 - 67, maio/ago. 2018.}

\section{DOI: $\mathbf{1 0 . 5 9 6 5 / 1 9 8 4 7 2 4 6 1 9 4 0 2 0 1 8 0 3 9}$}

http://dx.doi.org/10.5965/1984724619402018039 


\title{
When public policies fail, life is in danger: the struggle for housing
}

\begin{abstract}
The present paper seeks, from the critical reflection of a Public Civil Action that aims at the removal of a community in the city of Pelotas in the State of Rio Grande do Sul, to analyze macroprocesses of commodification of life and financialization of the urban territory. In methodological terms, it seeks to report from a specific case how a denial of the right of living develops. Introducing local legislation and analyzing the conduct of public policies for the interests of the real estate market in an attempt to denounce a model of territorial segregation.
\end{abstract}

Keywords: Popular Housing; Inequality; Public Policies; Irregular Occupation; Housing Policies in Pelotas; Territorial Property in Pelotas. 


\section{Introdução}

Recentemente passou a ser noticiado (COGOY, 2017), (MUNARETTO, 2017), e assim tem se tornado público, o processo que intenta a remoção das mais de 60 famílias que habitam um território reconhecido como Corredor da Estrada do Engenho, no município de Pelotas, estado do Rio Grande do Sul. É um processo movido pelo Ministério Público Estadual contra a Prefeitura Municipal, no qual a última é acusada de ser negligente na fiscalização das ocupações sobre as Áreas de Preservação Permanente (APP). Tal Ação Civil Pública (ACP) exige que o poder público local remova as famílias que ocupam a área e as realoque em um lugar que apresente condições saudáveis e seguras para moradia (RIO GRANDE DO SUL, 2016).

Sob tal alegação, o processo ainda acaba por criminalizar a comunidade residente no território, responsabilizando-a enquanto causadora de danos ambientais e destacando-a como habitante de área de risco.

Ao exigir a remoção das famílias sem considerar os processos históricos que as levaram a ocupar tal território, o processo acaba por ocultar mais do que esclarecer. Oculta o interesse especulativo e econômico do qual tem sido alvo esse território por parte de agentes construtores. Oculta as intenções do poder público local, expresso no III Plano Diretor. Oculta a negligência e descaso do mesmo quanto ao não cumprimento da legislação, que acaba por colocar tal comunidade nesta situação. Oculta que em sua planificação, as políticas públicas habitacionais não têm se voltado para seu público-alvo. Por fim, oculta que tal território é historicamente habitado por grupos de trabalhadores tradicionais e que o modelo de desenvolvimento adotado no município tem potencializado processos segregadores, agravando a manifestação da "questão social" expressão das contradições entre capital e trabalho.

Ao se debruçar sobre tal problema, analisando-o em suas macro-relações, a presente escrita buscará dar visibilidade aos conflitos e à racionalidade que tem guiado os a'gentes públicos locais. Ainda, problematizará, concordando com Santos (2009), a

\footnotetext{
${ }^{1}$ Por trabalhadores tradicionais, entende-se aqui os sujeitos que compõem os Povos e Comunidades Tradicionais, que são culturalmente diferenciados e que se reconhecem a partir de suas formas próprias
} 
produção do conhecimento que nega a experiência. Para isso, apresentará o fato de que muitos são os conhecimentos possíveis no mundo, e o reconhecimento destes deve ser considerado enquanto estratégia para a gestão democrática das políticas públicas e reinvenção da emancipação social.

\section{O processo de desigualdade e suas consequências na vida da população periférica}

Esse item tem o objetivo primeiro de problematizar o tema da desigualdade e sua relação com a vida da população periférica. Pretende lançar questões para que se crie um processo reflexivo sobre a chamada crise urbana e a necessidade de ocupações por parte da população empobrecida.

A desigualdade urbana é negada pela sociedade na medida em que se constroem mecanismos para esconder suas causas e consequências. É possível, por exemplo, identificar os impactos da desigualdade no meio ambiente e o papel regulador da lei no sentido de controlar a vida de quem vive na ilegalidade. A ilegalidade corresponde à realidade da vida dos citadinos que não conseguem integrar as normas formais do mercado em razão do empobrecimento multidimensional. No entanto, suas formas de existência manifestam a sua legitimidade, pois quem não tem moradia tem o direito de lutar para garantir o que está previsto na constituição federal brasileira.

Para Arantes; Vainer; e Maricato (2013, p. 155):

[...] ilegalidade não é fruto da ação de lideranças subversivas que querem afrontar a lei. Ela é o resultado de um processo de urbanização da população brasileira ter se dado, praticamente, no século $X X$, ele conserva muitas das raízes da sociedade patrimonialista e clientelista próprias do Brasil pré-republicano [...]. As resistências, que durante décadas, buscaram contrariar abolição do trabalho escravo marcaram o surgimento do trabalho livre. A cidade é, em grande parte, reprodução

de organização, ocupando e usando territórios e os recursos naturais para reprodução cultural, religiosa, econômica e ancestral, utilizando conhecimento, inovações e práticas gerados e transmitidos pela tradição (Decreto Federal n 6040, de 07 de fevereiro de 2000). 
da força de trabalho. Desde sempre, essa reprodução, entre nós, não se deu totalmente pelas vias formais e sim pelos expedientes de subsistência, que vigem até pleno final do século XX.

A cidade ilegal não compõe, não participa, não existe no mercado. A cidade ilegal não é cidade, pois onde vivem os citadinos empobrecidos não existe infraestrutura que garanta a sua permanência. Os citadinos aqui são os trabalhadores informais, desempregados, assalariados que não têm condições de adquirir moradia dentro das condições exigidas pelo mercado ou pelas condicionalidades impostas das políticas públicas para acessar a moradia. Segundo Ermínia Maricato (2015), essa realidade não é exceção, mas regra, porque diz respeito a uma parcela enorme e que compõe, em muitos casos, a maioria dos habitantes de determinados municípios no país. Uma grande questão que se apresenta é como os operadores do direito, advogados e juízes, conseguem conviver com a realidade fora da regra? Como os planejadores da cidade, poder público, concebem tal realidade? Os que estão fora da regra imposta pelos mecanismos legais, consequentemente, sofrem a punição por não se adequarem às normas para existir na cidade, e essa punição é naturalizada pela sociedade.

[...] A cidade legal é contemplada pelo poder público com investimentos e infraestrutura e é valorizada pelo mercado imobiliário. "A cidade ilegal" se refere à porção não reconhecida pelo poder público em termos de planos urbanísticos [...] como o lugar fora das ideias. (COSTA et al, 2018, p. 136)

As cidades brasileiras se encontram dentro da América Latina como as mais desiguais e não necessariamente as mais pobres. Em 2000, o Brasil estava entre os cinco piores distribuidores de renda, porém em 2015 caiu para décima quinta colocação (MARICATO, 2015). Assim, nesse período, houve uma modificação no padrão de distribuição de renda, especialmente no momento do aumento do salário mínimo acima da inflação, contudo a igualdade urbana não está necessariamente vinculada à distribuição de renda. Ermínia Maricato (2015) sugere distribuição de cidade, e não só de 
renda, para diminuir a desigualdade. As metrópoles, bem como as cidades de porte médio, são consideradas como violentas, mas essa realidade é vivida de forma desigual, ou seja, as condições para enfrentar a violência não são iguais. No que se refere a contingente periférico, este é, em muitos municípios, a maioria da população.

Como integrantes de um país da periferia do capitalismo, em que pesem as novas nomenclaturas definidas pelo mainstream, as cidades brasileiras carregam uma herança pesada. A desigualdade social, uma das maiores da América Latina, e a escravidão vigente até pouco mais de um século atrás são características que se somam a um Estado patrimonialistae à universalização da 'política do favor`. (MARICATO et al, 2013, p. 20)

A desigualdade na cidade é ignorada pelos mais diferentes citadinos e pelas instituições que determinam e regulam códigos de verdade definindo quem tem o direito à cidade. A população cada vez mais empobrecida não tem onde morar, entãoo que ela faz? Avança para locais onde exista espaço para construir o habitar. As áreas de proteção ambiental são um exemplo de ocupação desta população, pois de algum modo essas áreas não interessam para o mercado imobiliário e, consequentemente, acabam sobrando para a população pobre. Essa "sobra" faz aumentar o mercado informal de ocupações ilegais, apresentando tal deslocamento como única alternativa para as famílias de tentar construir espaços de moradia e de convivência mínima.

Para Maricato,

[...] a ausência de controle público sobre a propriedade da terra contribui para a carência habitacional, segregação territorial, aumento do custo da infraestrutura e serviços, aumento da violência de predação ambiental, além de impor maior sacrifício à população pobre excluída da cidade. A "desordem" do mercado fundiário e imobiliário (que evidentemente pressupõe uma outra "ordem") impõe custos à administração pública e amplia as desigualdades. (MARICATO, 2015, p.96)

Um elemento importante para refletirmos sobre a desigualdade enquanto crise urbana é percebermos que as questões da violência interferem profundamente no modo de vida da periferia. A violência para a classe média e alta acontece de forma distinta. $\mathrm{O}$ 
aumento das famílias chefiadas por mulheres também é uma característica das famílias que habitam a periferia. Essa característica manifesta a necessidade de as mesmas trabalharem fora do lugar que habitam, muitas são empregadas domésticas e são obrigadas a deixar os filhos em casa para buscar o sustento da família. No entanto, esses lugares ilegais não proporcionam mobilidade, gerando o exílio dos citadinos na própria cidade. Dessa forma, esses lugares produzem uma outra cidade, uma microcidade para que não haja deslocamento da periferia.

Outro elemento que se apresenta é a questão da saúde em relação à desigualdade. Relacionar o tema da saúde com a condição urbana possibilita analisar que as condições de vida urbana determinam os estados de saúde da população. A mobilidade é um exemplo que interfere na qualidade de vida e produz níveis de adoecimento mental, como depressão e ansiedade, por exemplo. Outra questão da saúde está relacionada à construção dos cômodos da população, que não têm ventilação e nem entrada para luz solar, produzindo doenças respiratórias. São condições que não garantem a qualidade de vida na própria casa.

As casas na periferia não são construídas em lugares salubres. É possível afirmar que a incidência de insetos e a disseminação de doenças na população pelo não controle por parte das secretarias municipais fragilizam ainda mais as condições de saúde para habitar nesse espaço urbano. O lixo e o saneamento não são atendidos, e a população busca saídas alternativas para seu descarte.

Hoje a exclusão não é percebida como resultado de uma momentânea e remediável má sorte, mas como algo que tem toda aparência de definitivo. Além disso, nesse momento, a exclusão tende a ser uma via de mão única. (BAUMAN, 2009, p. 23)

Outro tema necessário para discutir a crise urbana é sobre a localização. Morar bem está intimamente relacionado com as condições econômicas e sociais e com o local onde esta moradia será construída. O que significa? Significa que o local define o preço da habitação, ou seja, é o negócio da cidade que envolve parcerias com interesse de 
investimento público e privado. Essa questão deflagra uma guerra, pois para alguns a cidade é um meio de sobrevivência e para outros, um grande negócio (MARICATO, 2015).

A terra tem preço, e o preço muda conforme os interesses em um jogo que inevitavelmente gera a expulsão da população para as periferias urbanas. As construções para os megaeventos legitimam tal afirmação, porque em razão delas populações inteiras foram deslocadas: moradores em situação de rua, trabalhadores ambulantes, moradores irregulares, etc. Existem investimentos caros para esses acontecimentos que desconsideram o mal causado no cotidiano da população, como se deslocar para o trabalho, entre outras necessidades. Esse mal é considerado um processo de gentrificação. No referido processo, as populações são deslocadas para que as áreas, antes habitadas por elas, sofram uma mudança ocasionada pela especulação imobiliária, pautada no discurso da modernização do espaço da cidade. No entanto, a ocupação ilegal é aceita quando o grande capital, as forças da especulação imobiliária e o complexo imobiliário não têm interesse (ROLNIK, 2015).

A questão da mobilidade na cidade revela que os citadinos vivem uma boa parte de sua vida nos transportes urbanos em razão do tempo que são obrigados a permanecer neles, ou seja, é uma viagem de um bairro para outro ou do bairro para o centro da cidade. Outra problemática é o incentivo ao rodoviarismo: intensas e constantes obras rodoviárias que geram poluição e congestionamentos e que revelam à tragédia do discurso de modernização da cidade. Essa problemática interfere na qualidade de vida e ocasiona doenças e óbitos cardíacos por causa da poluição. Os automóveis também são os responsáveis pelo aquecimento global por causa do petróleo; mesmo assim, eles continuam aumentando e influenciando na qualidade de vida da população. Porque? Pelo interesse das grandes indústrias, do mercado e do capital financeiro internacional.

A condição da vida periférica depende do uso do transporte para acessar os serviços públicos, tornando a vida de quem vive na periferia um sofrimento em razão dos limites impostos pelo deslocamento. Os citadinos, para acessarem saúde, educação e, lazer, por exemplo, necessitam utilizar o transporte, no entanto, o gasto com deslocamento e a limitação de horários para atender as necessidades do grupo periférico 
impedem que possam acessar de forma qualificada as oportunidades oferecidas nos centros da cidade.

A segregação social torna invisível aos olhos da sociedade em que condições vive a população periférica. A informação sobre os números de loteamentos e ocupações nos municípios, em sua grande maioria, não são divulgados. Isso porque não há interesse de apresentar a realidade em que vive a população, uma situação de empobrecimento e desigualdade. Portanto, o direito à cidade no Brasil está ligado ao direito à propriedade, mas quem vive em situação ilegal e irregular não existe, não tem direito à cidade.

Sendo assim, se divulgados os dados da situação em que vive a ampla maioria, os gestores terão que construir mecanismos de resolução para garantir minimamente o que está previsto no Estatuto da cidade e na Constituição Federal de 1988. Ambos afirmam que todos têm direito à moradia, obrigando o Estado, através de seus governantes, a possibilitar o acesso a esse direito. Ainda, toda propriedade deve cumprir sua função social. Se não o fizer, esta deve ser redimensionada para tal objetivo, exigindo a fiscalização para fins de moradia com condições digna de sobrevivência.

Com a impossibilidade de adquirir moradia por via do mercado formal ou pelo acesso às políticas públicas, a população vai criando possibilidades de habitar o espaço etentando romper o que é imposto. Casas são auto construídas, pois as necessidades vão se ampliando com o aumento dos componentes da família. São construções em mutirão familiar ou entre famílias. Essa prática potencializa a resistência coletiva de se manter em lugares segregados, propicia a construçãodos vínculos e fortalece as histórias de vida que desenham nas ocupações urbanas.

Esses elementos apresentados permitem afirmar que o planejamento urbanístico não conta, não inclui as necessidades dos citadinos enquanto população periférica. $O$ planejamento urbano ocupa-se em responder às exigências do complexo imobiliário (ROLNIK, 2015) que decide na lógica da financeirização da terra de quem é a cidade, para quem é a cidade e o que é a cidade. Consequentemente, a decisão desse planejamento destrói com os modos de vida da população que vive na periferia, sendo a população composta por mulheres e negros, portanto, a desigualdade no Brasil tem gênero e raça. 
A construção ideológica que cerca o conceito de propriedade privada é tão forte que, numa inversão completa de papéis, homens e mulheres que deveriam se beneficiar da aplicação das leis, e em nome dos quais elas são aprovadas, são acusados de se insurgir contra elas. Aqueles que foram objetos de tantas leis ignoradas, os desterrados, os acampados, as vítimas da violência das milícias privadas ou mesmo públicas, aqueles que não possuem nada além da roupa do corpo e os instrumentos de trabalho são acusados de violência porque não aceitam o destino das favelas, do tráfico, das marquises nas ruas. (MARICATO, 2011, p. 190)

A população periférica não ocupa o espaço urbano de forma ilegal porque quer, mas porque não tem outra alternativa para sobreviver. A ocupação de terra acontece como alternativa para aqueles que não têm onde morar e não têm condições econômicas para consumir o produto que o mercado formal oferece. Não existe por parte da população pobre a necessidade de ocupar terra para ser um agente ilegal, o que existe é a necessidade de ter o direito à moradia atendido. A ocupação torna-se uma ação legítima porque existem milhares de famílias sem-terra, sem teto, sem emprego.

\section{O habitar espaço-temporal do território: desvelando o processo histórico}

Para compreensão de como se chegou aos processos recentes e de como os vários agentes têm incidência sobre o território alvo de disputa analisado pela presente escrita, desenvolve-se um breve resgate histórico sobre a origem da cidade de Pelotas atentando para o território do qual se pretende remover as famílias ali residentes. Esse território, em sua gênese, já se apresentava enquanto espaço onde comunidades de trabalhadores reuniam-se para desenvolver suas atividades laborais e residir.

Compreendendo que a cidade pode ser abordada de diversas formas, este primeiro relato histórico buscará situá-la apontando para a forma como se deu o desenvolvimento do processo de urbanização local. O referido processo engendrou, desde seu início, estratégias de alienação urbanística - produção do analfabetismo 
urbano através do desenvolvimento territorial subordinado à reprodução do capital (MARICATO, 2015), que tem na cidade um objeto estruturante das relações sociais.

Assim, nasce a cidade de Pelotas em 1812, batizada primeiramente de freguesia de São Francisco de Paula, alcunha que carrega de forma abreviada até os dias de hoje em sua bandeira. Entretanto, antes de ser elevada à freguesia e antes de atingir status de cidade, nessa sesmaria formou-seo Passo dos Negros, que foi o primeiro arraial do distrito (GUTIERREZ, 2001).

Originária de uma doação feita pelo então governador do Rio de Janeiro, conde de Bobadela, em 1758, a Tomás Luís Osório,a sesmaria de Pelotas foi dividida em cinco partes, das quais nascem as primeiras estâncias que sediaram as sete charqueadas que deram início à freguesia (GUTIERREZ, 2001). É nesse movimento de divisão territorial e desenvolvimento, impulsionado economicamente pelo fornecimento de alimentos para o resto do país, este intrinsecamente dependente da atividade laboral negra nas charqueadas, que nasce, a partir do Passo dos Negros, a cidade.

Na localidade onde se situava o Passo dos Negros tinha-se a principal porta de acesso à sesmaria, pois era o local em que se encontravam o atracadouro de navios e, ainda, um posto de cobrança de impostos para a coroa portuguesa (GUTIERREZ, 2001).

O território que estava localizado à margem do canal São Gonçalo foi aprimeira entrada do sítio charqueador pelotensee onde se iniciou o plantio e beneficiamento de arroz na região, atividades econômicas que marcaram o século XIX e início do Século XX. Quanto às datas de início do plantio e beneficiamento do cereal e encerramento do ciclo do charque existem imprecisões, mas o início do século XX é apontado como período dessa transição (RHEINGANTZ, 2004).

Assim, a mesma localidade, um século depois de surgir como Passo dos Negros área de entrada de escravizados e produção de charque - acaba por receber a instalação do primeiro engenho de beneficiamento de arroz, o Engenho São Gonçalo, também conhecido como Engenho Pedro Osório (ROSI, 2010). Este acaba por alterar a morfologia local e rebatizar o território que passa a se chamar de Corredor da Estrada do Engenho. 
Mapa 1 - Passo dos Negros

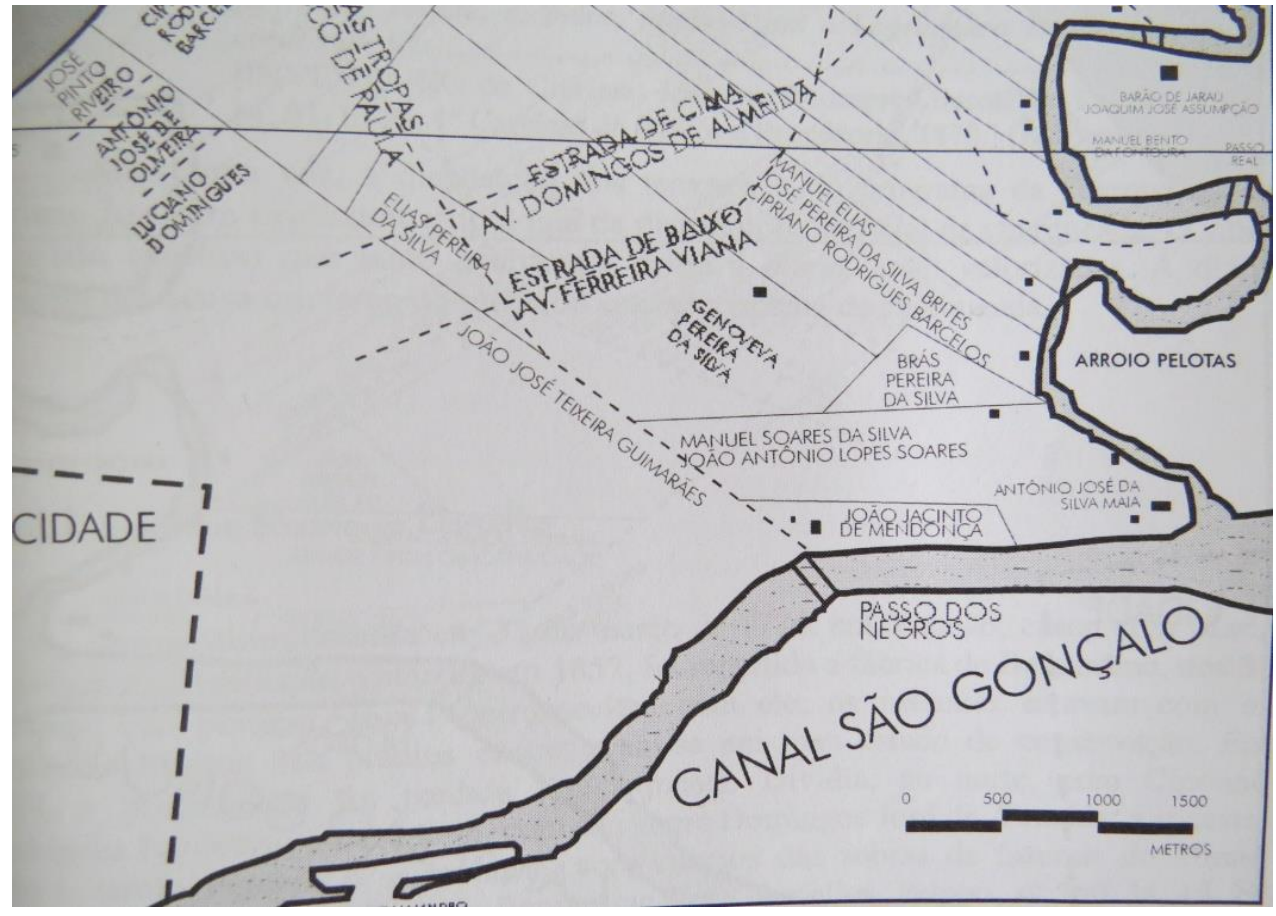

Fonte: GUTIERREZ, 2001, p. 143.

A partir da instalação do Engenho, tal território, que já era marcado pela presença negra, descendência daqueles que foram escravizados e trazidos para trabalhar nas charqueadas, passa a receber o acréscimo de uma vila de trabalhadores do Engenho e posteriormente de uma vila de pescadores (ROSENTHAL; GONÇALVES, 2014).

Por se tratar de uma área baixa e de fácil alagamento, propícia para o plantio de arroz, mas não para o desenvolvimento de habitações, o território acaba por ser deixado de lado no processo de desenvolvimento da cidade, quando se escolhem as áreas mais altas para fixação do centro do município e de moradias. Essa região, já nos primeiros movimentos em direção ao desenvolvimento urbano, torna-se um negativo a esta produção, pois nela permaneceram as comunidades tradicionais que foram 
impossibilitadas de deslocar-se para o centro da cidade e ingressar no mercado formal de terras (GUTIERREZ, 2001).

Para permanência em tal território, as famílias acabaram por desenvolver uma forma própria de se relacionar com o ambiente, relação esta com incidência sobre seu modo de habitar - viver e relacionar-se com e no território (LEFEBVRE, 2001) e sobre seu desenvolvimento de atividades laborais.

Mapa 2 - Estrada do Engenho

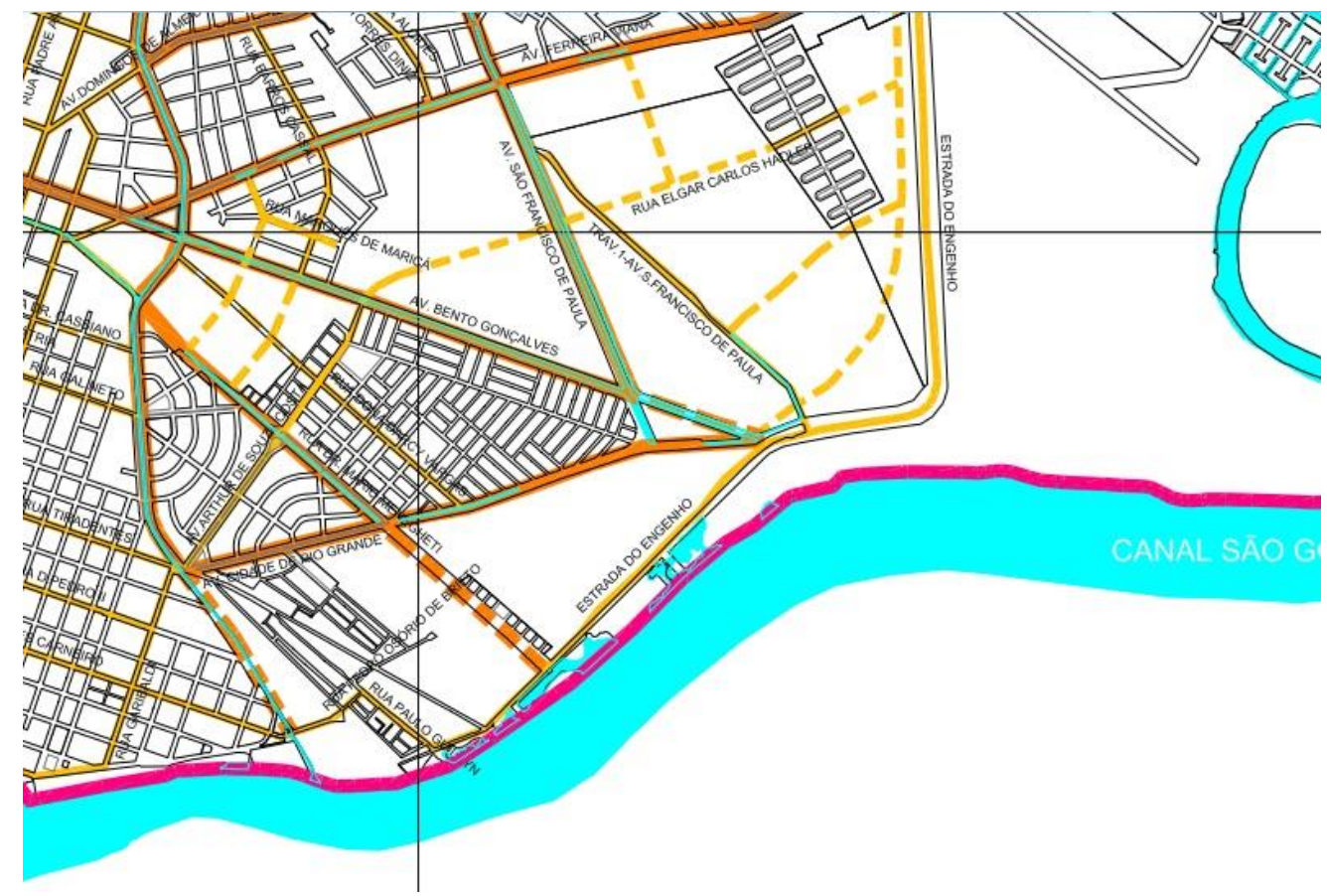

Fonte: PELOTAS, $2008^{\mathrm{a}}$.

Com o desenvolvimento da cidade, a margem do canal acaba sendo esquecida nos processos de urbanização, por não despertar o interesse dos grupos economicamente dominantes. Serve apenas para potencialização dos processos de segregação sócioterritorial, espaço de moradia àqueles que se encontravam em situação econômica vulnerável e em espaço de perpetuação do modelo de desenvolvimento urbano desigual e combinado (OLIVEIRA, 2013). Nesses espaços, a negação do acesso à cidade infraestrutura, equipamentos e serviços - criou o passivo para o desenvolvimento da cidade, sustentando uma das contradições intrínsecas da modernização capitalista, o 
negativo do desenvolvimento. A (im)produção que fortaleceu a falta de infraestrutura, generalizou a desigualdade (OLIVEIRA, 2013).

Nesse escopo, as últimas décadas foram de desenvolvimento de políticas públicas que se voltaram a sanar o problema de desenvolvimento urbano precário da localidade, tendo no ano de 2008 um marco no avanço desses projetos, quando da promulgação do III Plano Diretor Municipal (PELOTAS, 2008). Com o referido plano, avançou-se no objetivo a ser alcançado: a plena urbanização do território onde a cidade nasceu.

A ineficiência, porém, na planificação da lei do Plano Diretor somada à gestão da política pública de habitação - Programa Minha Casa Minha Vida (PMCMV) - focalizada nas faixas de maior lucratividade para o mercado imobiliário, e ao ocultamento do fato de serem populaçõestradicionais residentes no local, culminam no processo de remoção que tem se desenvolvido.

\section{Ocupação irregular: reflexo da negação dos direitos à moradia e à cidade}

A denúncia dos moradores ameaçados pelo processo de remoção tem incidência sobre o acelerado aumento da ocupação sobre o território habitado por estes. E os grandes empreendimentos imobiliários, os quais promovem a ocupação, não estariam dispostos a dialogar com as ocupações tradicionais. Marinas, atracadouros, condomínios de alta renda e empreendimentos comerciais têm buscado a localidade para desenvolverem-se nos últimos anos, ao mesmo tempo em que tem aumentado a procura e a ocupação do território por grupos que não conseguem acompanhar o aumento dos valores dos aluguéis, grupos que têm sido alvo do desemprego e de despejos. Reflexo da profunda desigualdade que se concretiza na negação do direito à moradia (BOULOS, 2015).

Deste modo dois movimentos distintos ocorrem no local. O primeiro é o das famílias que sem condições de se inserirem no mercado da moradia acabam por ocupar a localidade, por ser esta uma área próxima ao centro da cidade que até então não despertava o interesse dossetores privados da construção e que possibilitaria de alguma 
forma a manutenção de suas vidas. Sobretudo sendo essas famílias de catadores de resíduos sólidos e desempregados. O segundo movimento encontra-se no bojo do desenvolvimento de condomínios de alta renda, como se observará no mapa 4.

O primeiro movimento é denunciado na ACP - que acusa o município de negligência no trato com a fiscalização de Áreas de Preservação Permanente (APP). Relata-se que na última década "é veemente o aumento das ocupações clandestinas na área de preservação permanente (margens do Canal São Gonçalo)" (RIO GRANDE DO SUL, 2014, p. 4, 5). No entanto, não se destaca que as famílias que residiam anteriormente no local são famílias tradicionais, colocando, assim, todos em um mesmo grupo que estaria causando danos ambientais a uma APP e ainda ocupando uma área de risco por residir à margem do Canal.

O que está oculto nestas linhas é o fato de que são dois os grupos que têm ocupado este território. O primeiro é originário e divide-se em três: famílias de descendência dos escravizados, de descendência de trabalhadores do engenho e de pescadores. O segundo é o dos grupos excluídos do mercado formal de trabalho e terras, que é um grupo transitório. E o movimento deste último se dá por conta da financeirização e elitização do mercado da habitação, uma das principais marcas deste setor no país (BOULOS, 2015), e potencializador da busca de novas famílias por tal área na última década.

Para aprofundar a reflexão sobre esse processo serão analisados os levantamentos feitos para as áreas de ocupação irregular no município de Pelotas, relacionando-os à planificação do programa habitacional PMCMV na mesma localidade.

Assim, segundo levantamento feito entre os anos de 2008 e 2009 (ALVES), pelo supervisor de regularização fundiária do município de Pelotas, que foi apresentado à câmara de vereadores no ano de 2013, Pelotas apresentava 156 áreas de ocupações irregulares e clandestinas. Estas foram caracterizadas pelo poder público municipal como áreas que "embora aprovados pela Prefeitura e demais órgãos Estaduais e Federais, quando necessário, fisicamente não são executados, ou são executados em descompasso com a legislação ou com atos de aprovação" (ALVES, 2014, p. 3). São executadas para 
áreas de ocupação irregular; e, "aqueles que não obtiveram a aprovação ou autorização administrativa dos órgãos competentes, incluídos aí não só a Prefeitura, como entes Estaduais e Federais" (ALVES, 2014, p. 3), para áreas de ocupações clandestinas.

Segundo o mesmo estudo, nestas 156 áreas havia, em média 72 lotes, com cerca de 390 pessoas em cada uma das áreas. O que aponta para um número de mais de 11 mil lotes irregulares ou clandestinos no município, os quais habitavam mais de 60 mil pessoas. Os dados do último senso do Instituto Brasileiro de Geografia e Estatística (IBGE) para Pelotas - dados de 2010 - mostram que a cidade possuía cerca de 130 mil unidades habitacionais e 328.275 habitantes no ano. Se comparados estes números com os de habitação irregular, em 2013, mais de 8\% das habitações em Pelotas eram irregulares, e nestas se encontravam mais de $18 \%$ da população do município (IBGE, 2017).

Quanto ao déficit habitacional no mesmo ano, o Plano Local de Habitação de Interesse Social (PLHIS) do município aponta que havia um déficit de 13.598 moradias. Em tal cálculo incluem-se domicílios improvisados, precários, coabitação e famílias com situação de aluguel com valor excessivo, ou seja, famílias que gastavam mais de um terço de sua renda com aluguel (PLHIS, 2013a; PLHIS, 2013b).

Desta forma, fica claro que em 2013 o déficit habitacional do município era de mais de 10\%; deste percentual, mais de $80 \%$ era do que se considera déficit qualitativo, ou seja, de moradias já existentes, mas estando em situação irregular ou clandestina. Moradias estas que necessitavam de regulamentação documental e infraestrutura urbana, equipamentos e serviços como calçamento, saneamento, escolas, postos médicos etc.

No mesmo período - 2013 até 2016 - Pinto (2016) vai apontar que o município registrou a construção e entrega de 41 empreendimentos do PMCMV, totalizando 7.665 unidades habitacionais. Um número de habitações correspondente a $56 \%$ do déficit habitacional no município, apontado em 2013, fora produzido através de recursos públicos pelo programa. Este autor ainda aponta que as alterações promovidas pelo Ministério das Cidades a partir do ano de 2003 no setor habitacional brasileiro e, sobretudo, através do PMCMV "tiveram como objetivo o combate ao problema habitacional para a população de baixa renda" (PINTO, 2016, p. 55). População que, 
segundo os números analisados, representava em 2013 mais de 80\% do déficit habitacional do município.

Se levarmos em consideração que o estudo de Alves fora feito entre os anos de 2008 e 2009, sendo este último ano o do início da construção dos empreendimentos do PMCMV no município, o número de construções passa de 41, entre 2013 e 2016, para 60, entre 2009 e 2016. E o número de habitações construídas vai para 11.919 (PINTO, 2016).

A produção de habitações através do PMCMV no município de Pelotas, segundo os levantamentos, poderia sim ter acabado com o déficit da população de baixa renda, déficit expresso no problema qualitativo do município. População esta para a qual o programa foi desenvolvido, na ocasião de lançamento do programa pelo Ministério das Cidades. Todavia, segundo dados atualizados, nos anos subsequentes ocorreu um aumento significativo no tocante ao número destas áreas de ocupação irregular. Passaram para 162 áreas identificadas no ano de 2014 (ALVES, 2016), e no ano de 2017 já estão em um total de 205 áreas de ocupação irregular cadastradas somente no que é considerado perímetro urbano do município, pois o último levantamento não apresenta o perímetro rural (ALVES, 2017).

O estudo atualizado sobre as áreas de ocupação irregular aponta para o fato de que "mais de 90 mil pessoas" estão residindo em habitações em situação irregular, “quase 1/3 da população" do município (ALVES, 2017, p. 26). Segundo noticiado pelo Jornal Diário da Manhã (COGOY, 2017), em 05 de setembro do corrente ano, seriam já 100 mil pessoas.

O questionamento que resta após esses apontamentos é: Como foi possível produzir moradia suficiente para resolver o déficit habitacional do município, sobretudo para as populações alvo de tal política pública, e concomitantemente potencializar o aumento das ocupações irregularese da migração para o Corredor da Estrada do Engenho, como destaca a ACP? Ou seja, habitações foram produzidas, mas aumentou o número das famílias sem acesso à moradia no mesmo período. Como se deu este movimento? 
Para melhor compreensão, torna-se necessário refletir sobre o fato de a quem tem servido as políticas públicas, uma vez que se compreende que as áreas tidas como irregulares são na verdade o negativo do qual se alimenta o processo de urbanização e de onde será extraída a mais valia relativa.

\section{Quem controla a cidade}

Observando a escrita de Arantes, Vainer e Maricato (2013), que apontam para as bem orquestradas farsas que legitimam os projetos de grupos dominantes para as cidades, criando falsos consensos, cedendo espaços aos interesses empresariais e não atendendo às reivindicações populares, avança-se nesta reflexão. Atenta-se para o fato de que se está buscando solução para problemas estruturais históricos do município, mas a alternativa apontada na ACP é pontual e descolada da estrutura fundante do problema.

Assim também se lançará reflexão sobre o PMCMV. No trato com questões de cunho estruturais, ambos os processos carregam o mesmo discurso de solução para problemas estruturais, mas não vão além da estratégia para manutenção do poder das classes dominantes. É o favorecimento público ao setor privado (NABUCO; PRIMI; NABUCO, 2014).

A análise do PMCMV em sua planificação na cidade de Pelotas, para além de refletir a racionalidade descrita por Arantes, Vainer e Maricato, possibilita a compreensão dos questionamentos anteriores quanto àrelação da produção habitacional e ao aumento das ocupações irregulares no município. Jones Vieira Pinto, ao lançar reflexão sobre a planificação do PMCMV, destacaque "a influência dos agentes promotores privados sobre os direcionamentos e sobre a qualidade da produção do PMCMV" na cidade foi notável (PINTO, 2016, p. 220). O autor descreve leis municipais que foram alteradas sob tal influência para a aprovação de empreendimentos sem qualidade e "notavelmente prejudiciais ao tecido urbano de Pelotas" (PINTO, 2016, p. 220). Traça a reprodução do quadro que tem sido a lógica de execução do PMCMV ao redor do país, na cidade. 
Mesmo diante dos estudos e levantamentos feitos, que apontaram para o problema habitacional sendo de $80,89 \%$ qualitativo - moradias precárias, sem acesso mínimo a infraestrutura urbana, localizadas em áreas de risco socioambiental etc. e 19,11\% quantitativo, foram produzidas $76,49 \%$ das habitações para os grupos que têm renda acima de três salários mínimos, ou seja, para o grupo de renda que representava o déficit de 2.598 habitações, foram produzidas 8.837 habitações (PLHIS, 2013).

A produção do PMCMV em Pelotas é dividida por faixa de renda. Os números até dezembro de 2016 são de 2.856 habitações para faixa 3 - com renda de 4 a 9 mil reais $23,96 \%$ das moradias produzidas,e 6.251 moradias para faixa 2 - renda de 2,6 a 4 mil reais 52,45\% das moradias produzidas(PINTO, 2016).

Esses números, além de revelar uma total inversão de prioridade no ato de planificação da política pública, apontam para a priorização por parte das construtoras e incorporadoras das faixas de maior lucratividade. Esclarecem, ainda, o porquê de não se ter avançado em direção à solução dos problemas habitacionais locais. Em vez de se investir em regularização fundiária e urbanismo, optou-se pela produção de novas moradias, e tal produção voltou-se para as faixas de maior renda.

Deste modo, apenas $23,59 \%$ das moradias foram produzidas para a faixa $1-2.812$ moradias - a menor porcentagem foi destinada para o grupo que seria o alvo da política, e, segundo os levantamentos locais, aquele que mais carecia de investimentos.

Entre as leis municipais que foram criadas e alteradas no decorrer do PMCMV, estáa Lei 5.603/2009, que instituiu o programa habitacional de interesse social "Pelotas Habitação Digna", que viabilizou a construção de um maior número de habitações dentro do PMCMV. Além de não apresentar adendos quanto à qualidade para seus usuários, trouxe isenções de impostos sobre a construção dos empreendimentos para seus executores (PELOTAS, 2009).

Outra lei é a 5.963/2012, aprovada no dia 28 de dezembro de 2012, três dias antes do final do mandato do então prefeito Adolfo Antonio Fetter Junior (PELOTAS, 2012), que alterou o perímetro urbano para que se produzissem habitações ainda mais distantes. Essa lei favoreceu a diminuição e até mesmo a dispensa de áreas verdes e áreas de uso 
público no interior dos empreendimentos, como era previsto, anteriormente, em lei. Esse alargamento não ocorreu de forma fortuita, segundo Pinto (2016, p. 225), “pois possibilitou o projeto e construção de dois dos empreendimentos pertencentes ao PMCMV [...], e onde os dois empreendimentos foram instalados extrapola os limites do perímetro urbano".

As influências de agentes promotores privados sobre as leis do município são evidentese visaram especificamente à facilitação da lucratividade das empresas privadas.

Desse modo, as 11.919 unidades habitacionais produzidas com financiamento público através do PMCMV na cidade (PINTO, 2016)não resolveram, tampouco diminuíram, o número das áreas de ocupação irregular, mas incidem diretamente sobre esse processo.

A cidade transformada em sujeito econômico, de natureza mercantilizada, empresariada "instaura o poder de uma nova lógica, com a qual se pretende legitimar a apropriação direta dos instrumentos de poder público por grupos empresariais privados" (ARANTES; VAINER; MARICATO, 2013, p. 89).

Assim, através da disponibilização de recursos, da administração das leis de zoneamento, de parcelamento do solo, bem como do desenvolvimento dos planos urbanísticos, relega-se ao poder privado o domínio da decisão quanto à produção da cidade. É possível o questionamento da afirmação de falta de fiscalização do poder público na ACP ao desvelar que a ocupação territorial, o desenvolvimento e a planificação das legislações no município atrelam-se a interesses outros.

\section{A modernização conservadora do III Plano Diretor}

O III Plano Diretor do Município de Pelotas (PELOTAS, 2008) surge reforçando os avanços do Estatuto das Cidades (BRASIL, 2001), apontando para o cumprimento da função social da cidade e da propriedade e reconhecendo a multidimensionalidade das potencialidades do município. Além disso, reitera a garantia do direito à cidade, entendido como "direito à terra urbanizada, à moradia, ao saneamento ambiental, à 
infraestrutura, ao transporte , aos serviços públicos, ao trabalho e ao lazer" (PELOTAS, 2008, p. 2), bem comosalientaa gestão democrática e participativa na execução das políticas territoriais.

Sobre o território e as populações trabalhadas nesta escrita, o documento destaca em seis artigos distintos os procedimentos a serem desenvolvidos para integração destes à cidade, apontando para o fato de que se deve "evitar a expulsão de seus moradores, mediante a utilização de instrumentos jurídicos" (PELOTAS, 2008, p. 36), reconhecendo tal território como uma Área Especial de Interesse Social (AEIS), localizada em "área de preservação ambiental e ocupada por população de baixa renda" (PELOTAS, 2008, p. 38).Por fim, classifica-a como uma Área de Preservação Permanente Ocupada (APPO).

Em cada um dos seis artigos - 60, 87, 88, 90, 91, 92, 93 (PELOTAS, 2008) - a legislação desenvolve uma série de ações específicas, que vão do desenvolvimento de estratégias para geração de trabalho e renda, regularização fundiária, desenvolvimento de infraestrutura urbana, disponibilização de recursos para recuperação das moradias até a recuperação ambiental dasáreas degradadas. E é na negligência total dessa lei, no vácuo deixado entre sua promulgação e efetivação, que se desenvolve a ACP $022 / 1.14 .0007280-6$.

Esta que, ao exigir a remoção da comunidade residente à margem do canal São Gonçalo, no local conhecido como Corredor da Estrada do Engenho, fazendo-o sem consultar, ou até mesmo ouvir os residentes locais, fere na essência o princípio da participação democrática anteriormente descrita.

Para melhor compreender esse macroprocesso, entende-se como necessário analisar, para além do que expõe a lei do Plano Diretor, como tem se dado o desenvolvimento do entorno do território, que passa a ser tratado na última década como área de conflito para posteriormente retornar à lei.

Como relatado, o desenvolvimento do município, por muito tempo, deu-se de costas para esse território, avançando sobre as áreas geograficamente mais elevadas, deixando para traz um grande número de vazios urbanos, relativamente próximos ao centro da cidade. 
Mapa 3 - Vazios Urbanos

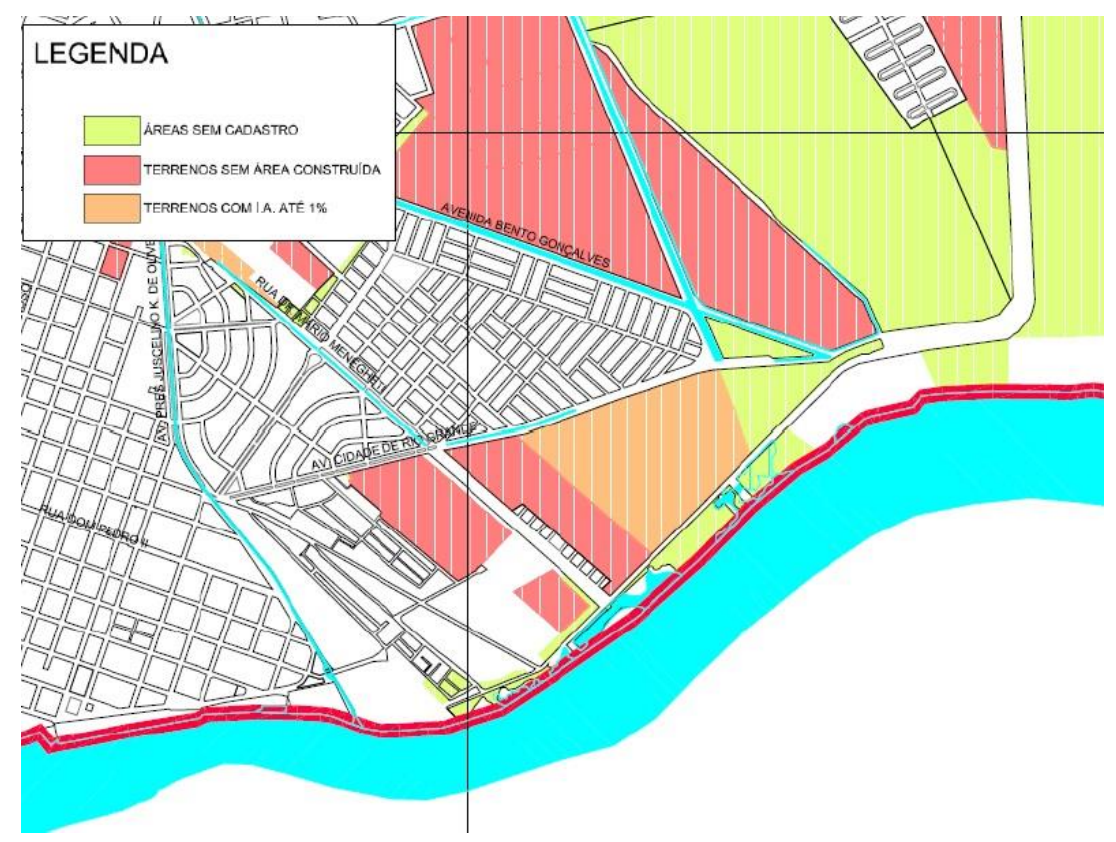

Fonte: PELOTAS, 2008b.

Desta forma, após o desenvolvimento das anticíclicas estratégias de desenvolvimento adotadas pelo Governo Federal, após o ano de 2008, que injetaram grandes quantias de dinheiro nos setores privados da construção (RODRIGUES; SALVADOR, 2011), (BOULOS, 2015), tal território passou a despertar a atenção de construtoras e incorporadoras capitalizadas e interessadasna manutenção do crescimento desse mercado.

Assim, os últimos anos foram marcados pela atração ao território de grandes empreendimentos, que vão da instalação de um campus da Universidade Federal até um shopping center, passando pelo desenvolvimento de marinas e degrandes empreendimentos imobiliários.

Assim, voltamos à lei do Plano Diretor, que em sua modernização conservadora acaba por retornar ao território e incentivar após dois séculos o modelo desigual e 
combinado de desenvolvimento urbano. O referido modelo não planifica as medidas que resolveriam os problemas urbanísticos e acena para o mercado a partir de um projeto de ampliação do centro urbano do município para tal localidade, com o desenvolvimento de atrativos que incentivem "a expansão da centralidade até o Canal São Gonçalo" (PELOTAS, 2008, p 8). Um movimento já bastante conhecido no tocante ao desenvolvimento urbano brasileiro (GONÇALVES, 1995), mas que se redefiniu a partir do favorecimento público (MARICATO, 2015).

Mapa 4 - Vista aérea dos Empreendimentos desenvolvidos após 2008 e dos vazios urbanos no território.

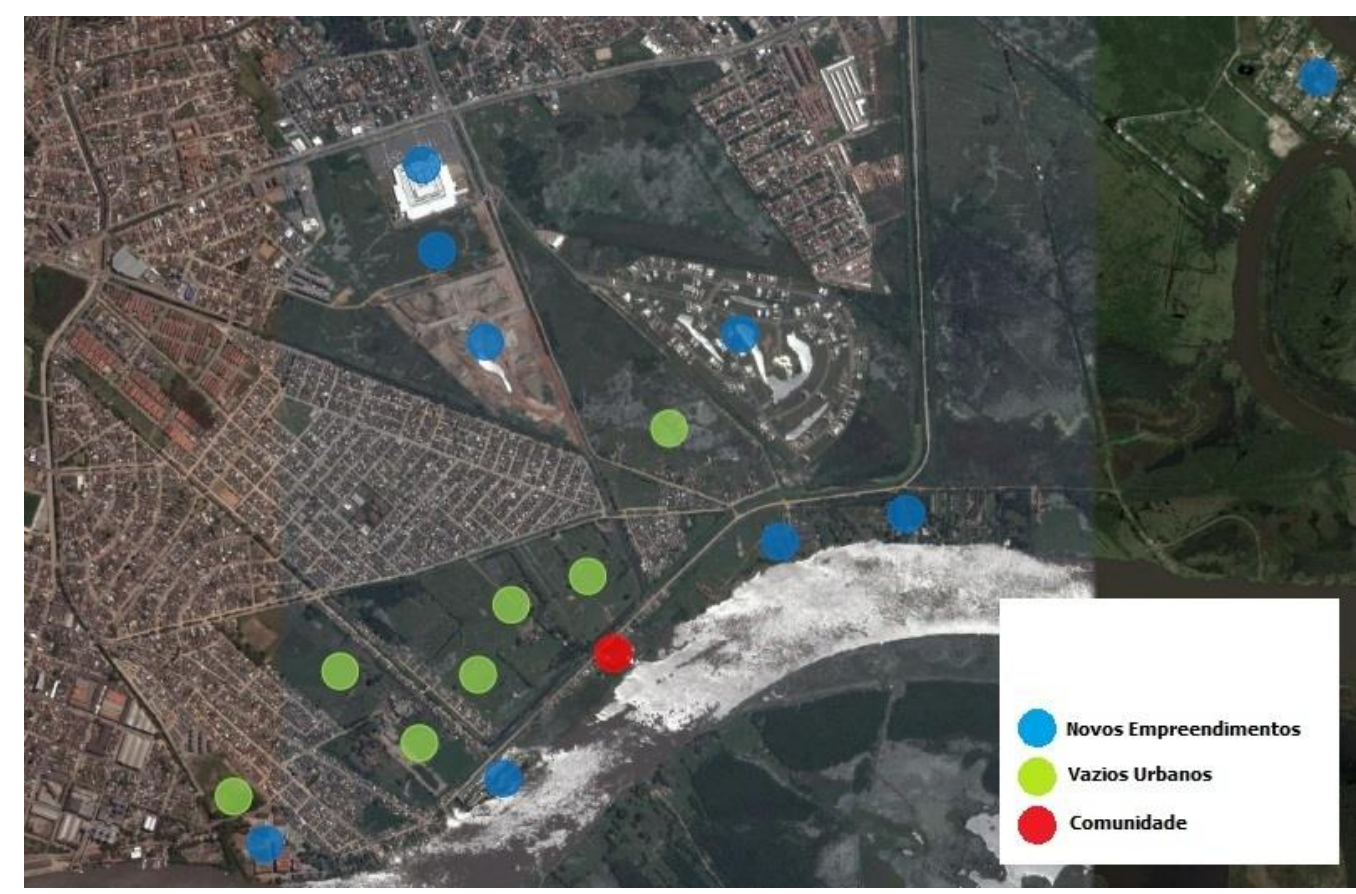

Fonte: imagem do Google maps.

Retornando a ACP após o desenvolvimento de tal reflexão e observando o mapa 4, questiona-se a intenção desta em apontar que: 1) Seria a área ocupada considerada de risco por estar à margem do Canal? Mas se existem outras ocupações na mesma situação, onde estaria a diferença entre elas? 2) Havendo a execução das políticas públicas específicas para o local, que tratam do desenvolvimento de infraestrutura urbana, saneamento e etc. que apontam para o desenvolvimento de um projeto específico de 
acordo com as legislações ambientais, continuariam as famílias ameaçadas de remoção por causar danos ambientais? 3) Sendo as políticas habitacionais (PMCMV) trabalhadas de forma a contemplar as populações-alvo de seu desenvolvimento, sendo os direitos constitucionais à moradia e ao trabalho garantidos, grupos em situação de vulnerabilidade social e econômica continuariam a procurar tal área para fixar residência e desenvolver suas atividades laborais?

Sobre cada um desses questionamentos poder-se-ia desenvolver uma nova escrita, mas o fato é que a remoção não solucionaráos problemas apontados pela ACP. Deixará, sim, o território livre para o desenvolvimento de novos empreendimentos que servirão aos grupos economicamente dominantes, retroalimentando a mesma racionalidade de desenvolvimento urbano.

Dessa forma, a remoção não pode ser uma opção. É, sim, um processo com incidência sobre o aumento do número de famílias que têm procurado tal território na última década, resultado da opção por um modelo específico de desenvolvimento urbano, que nega direitos em detrimento da garantia da acumulação capitalista.

\section{Considerações Finais}

O presente artigo pretendeu tornar-se instrumento para potencializar a luta das populações citadinas que vivem em situação de pobreza e desigualdade, mas que resistem na ocupação do solo urbano, denunciando o planejamento urbanístico voltado para o mercado formal e as políticas que negam o direito à moradia.

Manifesta, ainda, a contradição proposta pela Constituição Federal de 1988, que garante o direito à moradia e a implantação do Estatuto da cidade como instrumento para viabilizar esse direito no território nacional. Por sua vez, o plano diretor, nos municípios, obriga a pensar a cidade como direito de todos. A contradição está na legislação em determinado momento, pois deixa clara a defesa da função social da terra e, conseqüente, o direito de existir dos ocupantes, porém os operadores da lei não relacionam com o que está determinado nestes três arcabouços legais: Constituição 
Federal, Estatuto da Cidade e Plano Diretor, viabilizando com isso despejos e remoções violentas de inúmeras famílias.

Sendo assim, o direito à propriedade na constituição brasileira está subordinado à função social da cidade, essa brecha mostra que esse direito não é absoluto, mas o direito à moradia sim. Isso significa dizer que o direito coletivo é mais forte do que o direito individual privado. Portanto, os processos de segregação social desrespeitam o que está registrado nas leis que garantem o direito de habitar de todos. Ou seja, em nosso cenário nacional, o direito à propriedade está sendo aplicado às custas do direito maior, que é o direito daqueles que não têm como comprar terra e moradia. Essa relação contrária é resultado das alianças econômicas e políticas que desejam acelerar os processos de especulação imobiliária nos municípios brasileiros.

O caso relatado no município de Pelotas evidencia que tal realidade representa as condições em que vivem as populações em situação de posse e, arrisca-se afirmar, sob condição negada em seu direito de existir nos diferentes Estados do Brasil. Assim, o caso de Pelotas não é exceção, mas regra nacional. 
ALVES, Jorge. Apresentação 02. Pelotas, 27 de junho de, 2016. 48 slides. Apresentação em Power Poit.

ALVES, Jorge. Regularização fundiária: a cidade que temos e queremos. Pelotas, 7 de julho de, 2017. 337 slides. Apresentação em Power Poit.

ALVES, Jorge. Regularização fundiária. Pelotas, 16 de outubro de, 2014 . 320 slides. Apresentação em Power Poit.

ARANTES, Otília; VAINER, Carlos; MARICATO, Ermínia. A cidade do pensamento único: desmanchando consensos. 8. ed. Petrópolis: Vozes, 2013.

BAUMAN, Zygmunt. Confiança e medo na cidade. Rio de Janeiro: Jorge Zahar, 2009.

BOULOS, Guilherme. Por que ocupamos? uma introdução à luta dos sem teto. São Paulo: Autonomia Literária, 2015.

BRASIL. Lei Federal n..$^{\mathbf{1 0}} \mathbf{2 5 7}$, de 10 de junho de 2001: regulamenta os arts. 182 e 183 da Constituição Federal. Estabelece diretrizes gerais da política urbana e dá outras providências. Estatuto da Cidade. 2001. Disponível em:

<http://www.planalto.gov.br/ccivil_03/leis/leis_2001/l10257.htm> Acesso em: 13 maio 2014.

COGOY, Carlos. Famílias lutam contra a remoção. Diário da Manhã, ano 39, n.62, p.6, 4 set. 2017.

COGOY, Carlos. Regularização fundiária: Pelotas possui mais de 200 áreas irregulares.

Diário da Manhã, ano 39, n.63, p.8, 5 set., 2017.

COSTA, Sandra Maria Fonseca da et al. Entre a cidade legal e a cidade ilegal: a realidade das pequenas cidades da Amazônia - Um estudo de Ponta de Pedras, Pará, 2018. Disponível em <http://www.scielo.br/pdf/urbe/v6n1/v6n1a10.pdf|> Acesso em 20 março 2018.

ROSSI, Paulo. Antigo Engenho será Restaurado. Diário da Manhã, 24 mar 2010. Disponível em

<http://www.correiodopovo.com.br/Impresso/?Ano=115\&Numero=175\&Caderno=9\&Notici $a=116098>$ Acesso em 9 set 2017.

GONÇALVES, Maria Flora. O novo Brasil Urbano. Porto Alegre: Mercado Aberto, 1995.

GUTIERREZ, Ester. Negros, Charqueadas e Olarias: um estudo sobre o espaço pelotense.

Pelotas: Ed. UFPEL, 2001. 
IBGE. Pelotas, 2017. Disponível em:

<http://cidades.ibge.gov.br/xtras/perfil.php?codmun=431440> Acesso em: 2 jul. 2017.

LEFEBVRE, Henry. O Direito à cidade. São Paulo: Centauro, 2001.

MARICATO, Ermínia. Para entender a crise urbana. São Paulo: Expressão Popular, 2015.

MARICATO, Ermínia. et al. Cidades rebeldes: passe livre e as manifestações que tomaram as ruas do Brasil. São Paulo: Boitempo: Carta Maior, 2013.

MARICATO, Ermínia. O impasse da política urbana no Brasil. Petrópolis: Vozes, 2011.

MUNARETTO, Sara. Estrada do Engenho resiste: a luta de uma comunidade pelo direito à moradia. Repórter Popular, Porto Alegre, 6 set 2017. Disponível em $<$ http://reporterpopular.com.br/estrada-do-engenho-resiste-luta-de-uma-comunidadepelo-direito-moradia/>Acesso emg set 2017.

NABUCO, Aray; PRIMI, Lilian; NABUCO, Wagner. Luta por um Teto. Revista Caros Amigos, jul. 2014. Entrevista Guilherme Boulos.

OLIVEIRA, Francisco. Crítica a razão dualista o ornitorrinco. São Paulo: Boitempo, 2013

PELOTAS. Lei Municipal $\mathbf{n} .^{\circ}$ 5.502, de 11 de setembro de 2008: institui o Plano Diretor Municipal e estabelece as diretrizes e proposições de ordenamento e desenvolvimento territorial no município de Pelotas, e dá outras providências. 2008. Disponível em: <http://www.pelotas.com.br/politica_urbana_ambiental/planejamento_urbano/III_plano_ diretor/lei_iii_plano_diretor/arquivos/lei_5502.pdf>. Acesso em: 5 dez. 2015.

PELOTAS. Lei Municipal $\mathbf{n} .^{\circ}$ 5.502, de 11 de setembro de 2008: Institui o Plano Diretor Municipal e estabelece as diretrizes e proposições de ordenamento e desenvolvimento territorial no município de Pelotas, e dá outras providências. Mapa temático U12, vazios urbanos. 2008a. Disponível em:

<http://www.pelotas.com.br/politica_urbana_ambiental/planejamento_urbano/III_plano_ diretor/lei_iii_plano_diretor/arquivos/U12_VAZ̄IOS_URBANOS_IIIPD.pdf $>$. Acesso em: 9 set. 2017.

PELOTAS. Lei Municipal $\mathbf{n} .^{\circ}$ 5.502, de 11 de setembro de 2008: institui o Plano Diretor Municipal e estabelece as diretrizes e proposições de ordenamento e desenvolvimento territorial no município de Pelotas, e dá outras providências. Mapa temático U03, sistema viário - hierarquias. 2008b. Disponível em:

<http://www.pelotas.com.br/politica_urbana_ambiental/planejamento_urbano/III_plano_ diretor/lei_iii_plano_diretor/arquivos/Uo3_VIARIO_HIERARQUIA_IIPD.p̄pdf $>$. Acesso em: $\overline{9}$ set. 2017.

PELOTAS. Lei Municipal n. ${ }^{\circ}$ 5.603, de 3 de agosto de 2009:Institui o Programa Habitacional de Interesse Social "Pelotas Habitação Digna”, e dá outras providências, 
2009. Disponível em: <https://www.leismunicipais.com.br/.../pelotas/lei.../5603/leiordinaria-n-5603.pdf>. Acesso em: 25 jan. 2015.

PELOTAS. Lei Municipal $\mathbf{n} .^{\circ}$ 5.963, de 28 de dezembro de 2012: altera o perímetro urbano do município de Pelotas, e dá outras providências. 2012. Disponível em:

<http://www.pelotas.rs.gov.br/interesse_legislacao/leis/2012/LEl5963.pdf>Acesso em: 26 jun. 2016.

PLHIS - Plano local de habitação de interesse social de Pelotas - Etapa 3: estratégias de ação. Pelotas: 3C Arquitetura e Urbanismo, 2013. 63 p.

PLHIS - Plano Local de Habitação de Interesse Social de Pelotas, 2013a. Disponível em: <plhispelotas.blogspot.com> Acesso em: 22 maio 2014.

PINTO, Jones Vieira. Contribuições para estudo do "Programa Minha Casa, Minha Vida" para uma cidade de porte médio, Pelotas-RS: caracterização das empresas construtoras e incorporadoras privadas e inserção urbana. 2016. Dissertação (Mestrado em Arquitetura e Urbanismo) - Universidade Federal de Pelotas, Programa de Pós Graduação em Arquitetura e Urbanismo, Pelotas, 2016.

RHEINGANTZ, Carlos Guilherme. O charqueador. Diário Popular. Pelotas, ano 114, n.274, p.3, 9 jun., 2004.

RIO GRANDE DO SUL. Acordo judicial firmado sobre a ação civil pública $\mathbf{n}^{\circ}$ 022/1.14.0007280-6. em 21 nov. 2016. 2016. Disponível em: <http://www1.tjrs.jus.br/busca/?tb=proc> Acesso em: 09 set 2017.

RODRIGUES, Taíla Albuquerque; SALVADOR, Evilasio. As implicações do Programa de Aceleração do Crescimento (PAC) nas Políticas Sociais. SER Social, Brasília, v. 13, n. 28, p. 129-156, jan./jun. 2011.

ROLNIK, Raquel. Guerra dos Lugares: a colonização da terra e da moradia na era das finanças. São Paulo: Boitempo, 2015.

ROSENTHAL, Mariane D’Avila; GONÇALVES, Eduarda Azevedo. Marambaia História, Memória e Poética: Revista do centro de Artes da Universidade Federal de Pelotas, n. 4, 2014. Disponível em:

<https://periodicos.ufpel.edu.br/ojs2/index.php/Arte/article/view/4810/3592> Acesso em: 09 set 2017.

SANTOS, Boaventura de Sousa. "Para além do pensamento abissal. Das linhas globais a uma ecologia de saberes". SANTOS, B. S. e MENEZES, M. P. Epistemologias do Sul. Coimbra: Almedina, 2009. 
Recebido em: 30/03/2018

Aprovado 07/08/2018

Universidade do Estado de Santa Catarina - UDESC

Centro de Ciências Humanas e da Educação - FAED

Revista PerCursos

Volume 19 - Número 40 - Ano 2018 revistapercursos@gmail.com 